\title{
15 Investing in the True Value of Sustainable Food Systems
}

\author{
Tim Crosby, Jennifer Astone and Rex Raimond
}

How can investment and creative finance support healthy and equitable food systems shifts? More donors, investors, and members of the finance community are seeking integrated, holistic methods to assess investments. Social enterprises are also looking to demonstrate the value add of their impact. Recently, the Transformational Investing in Food Systems Initiative (TIFS Initiative) (www.tifsinitiative.org) adapted The Economics of Ecosystems and Biodiversity for Agriculture and Food's True Cost Accounting Framework (TEEB for Agriculture \& Food) (http://teebweb.org/agrifood/) into a tool for investors and entrepreneurs and have piloted the application of the tool. This chapter examines the strengths and weaknesses of such a tool for impact investing for food systems transformation and offers early case studies of how entrepreneurs and fund managers are looking to support equitable, agroecological food systems.

- Sistema Bio designs, builds, and sells patented biodigesters to small-scale farmers in Mexico, Nicaragua, Colombia, Kenya, and India. The biodigesters convert cow manure into energy and fertilizer, saving farmers money while protecting groundwater and improving soil health.

- Community Markets for Conservation (COMACO) works with 81 community cooperatives in Zambia to provide incentives for biodiversity conservation, support 188,500 small-scale farmers, apply climate smart agriculture, and run a business to manufacture and sell healthy foods.

- Root Capital is a non-profit social investment fund that invests in businesses that collect, aggregate, process, and market crops for rural farmers in Latin America, sub-Saharan Africa, and Southeast Asia.

Each case demonstrates a business model or investment approach that aims to create positive outcomes across Natural, Social, Human, and Produced Capital. They provide insight about how an applied TCA framework can be a helpful tool to shift how investment decisions are made.

\section{A True Cost and Value Approach to Investing}

Investing towards personal and ethical values has been promoted since ancient times (CNote, 2019), while values-aligned investing in North America got started in the 1960s social and political movements boycotting companies involved in the Vietnam War. Today, sustainable investing has expanded into Socially Responsible Investing, 
Environmental and Social Governance screening, the Global Reporting Initiative, Impact Investing, and most recently Blended and Integrated Capital Investing (RSF Social Finance, n.d.). By $2018 \$ 30$ trillion was invested globally with considerations of ethics, social and environmental values (Global Sustainable Investment Alliance, 2019). Data show that funds aligned with sustainable investing better estimate the true value of the underlying assets and their future values and are also outperforming many of their peers (Mooney, 2002).

While the field of sustainable investing has exploded, the ability to qualify and quantify the positive non-financial impact of an investment has not been standardized. However, the hunger for a global set of standards is witnessed by the way investors and fund managers quickly adopted the United Nations (UN) Sustainable Development Goals (SDGs). While the 17 SDGS include a total of 247 indicators, they contain scant guidance on what data sets are valid and standardized. In order to scale sustainable investing, investors and companies need a common approach and shared metrics to measure impact, and have these approaches and metrics align with accounting standards.

Prior innovations in investing have worked within the structure of Generally Accepted Accounting Principles (GAAP) and International Financial Reporting Standards (IFRS). With pressure from investors and associations like the Sustainability Accounting Standards Board (www.sasb.org), GAAP has begun implementing revisions that allow hitherto undervalued accounting items to be included in formal reporting requirements.

Investors, especially asset managers, are demanding more. They want to know that their impact is measurable and that those measurements are linked to overarching frameworks like the SDGs. By aligning investment criteria with True Cost Accounting (TCA), there is an opportunity to account for underlying material costs not currently captured in GAAP and IFRS as well as align values-based investment interests with needed accounting standard revisions. This should better connect the front-end decision-making of where to invest with the reporting of outcomes from that investment.

\section{Opportunities for True Value Investing in Aligned Food Enterprises}

Food systems transformation is central to the agenda for achieving a more just and sustainable world (Global Alliance for the Future of Food, 2020). Given food systems' undeniable links to climate change, migration, zoonotic disease, biodiversity loss, structural inequality, and public health-the myriad global emergencies that people currently face-transformation of these systems has emerged as a global priority.

Despite the rising voice for systems change, institutional investors, governments, philanthropists, and private sector companies seek enterprise or fund level success, not always system success. They generally seek to reduce their exposure to risks that they perceive as significant (e.g., financial loss, climate change, natural resource degradation, social inequality, food insecurity, or rising costs of healthcare), and might have divergent mandates (e.g., capital preservation, generating 
income and profit, and/or creating public goods). The need is to address these issues and mandates together in a more holistic approach to investing.

Investors - individuals, asset managers, and institutions - are being asked at an ever-increasing rate to prove the impact of their investments beyond financial returns. Social entrepreneurs are learning how to demonstrate the social and environmental value of their business to investors and donors. These needs require harmonizing multiple priorities, risk mitigation, and return expectations with the metrics to show positive outcomes for food producers, food workers, natural systems as well as consumer and community health. The biggest hurdles for the needed innovations in investment practices involve redefining risk, reward, efficiency, and scale to become more systems-focused, internalizing those considerations into decision-making structures, and agreeing on missing impact metrics. These innovations must overcome the current biased metrics for food systems investors that primarily reward two dimensions: increasing productivity and profit, a reductionist approach to food production.

Enter the United Nations Environment Program's TEEBAgriFood initiative which delineates costs and values across four types of "Capitals": Natural, Human, Social, and Produced. This holistic framework is being applied to create tools for business to develop comprehensive profit and loss reports that integrate value added or lost (e.g., I360X, True Price/Impact Institute, Harvard Impact Weighted Accounts, Common Land), explore the creation of new accounting standards (e.g., Sustainable Accounting Standards Board), and help agri-food companies to measure and manage their impacts, dependencies, and risks, and unlock new opportunities (e.g., World Business Council on Sustainable Development and Capitals Coalition). In the long run, these efforts can assist investors in identifying companies that are performing financially and creating better environmental and social benefits than their peers. To help diverse investors work together more effectively, an investing approach that incorporates the TEEBAgriFood framework analysis can elucidate and organize the anticipated negative and positive outcomes of a given enterprise's activities before an investment is made, while leveraging the framework's focus on the accounting sector.

\section{Applying TCA Rapid Assessments}

The Transformational Investing in Food Systems (TIFS) initiative has identified the need for practical decision-making tools that holistically identify the social and environmental impacts of enterprises. TIFS is piloting two TCA Rapid Assessment tools: one to assess impacts of social enterprises and one for investment funds (prototypes are being tested and will be made available publicly).

The goal of these TCA tools is to help investors and entrepreneurs assess enterprises' impacts on Natural, Human, Social, and Produced Capital stocks of food systems. The TCA tools are a set of questions that make each of the four Capitals visible to an investor and those seeking investment. The TCA tools pose outcome-oriented questions related to the four Capitals for consideration during normal due diligence processes; for example, "Does this investment increase or decrease Pollination? Does this project improve or reduce Community Wellbeing?" TIFS advances these tools as 
one lever to influence up-front investment decisions and back-end reporting and helps entrepreneurs to make a case in the absence of robust public policy that prices externalities. This converges with ongoing efforts to harmonize impact strategies, metrics, and data, as well as efforts to create new accounting standards and profit and loss reports.

Just as the development of financial analysis methods has enhanced investors' capacity to predict and improve financial returns, systematic impact analysis - both before and after investment - is in high demand and still needs work. The following examples highlight funds and enterprises that aim to achieve system-level impact. These established enterprises and investment funds used our first version of the TCA tools to track changes in Capital from a systems perspective. The following cases agreed to be engaged in this process. They are illustrative examples involving two enterprises and one fund that are leaders in their fields. The analysis and synthesis that follow incorporate feedback from almost 30 interviews with investors, fund managers, enterprises, and other experts, and a comparative review of major impact management and measurement frameworks. The results of the case examples, interviews, and review of the field of impact investing have informed the tool and the ensuing analysis.

\section{Sistema Bio}

Sistema Bio (https://sistema.bio) designs, builds, and sells patented biodigesters to small-scale farmers to convert manure into energy and fertilizer. Their low-cost, modular biodigesters save farmers money while protecting groundwater and improving soil health. Since 2010 Sistema Bio has installed over 11,000 units in Mexico, Nicaragua, Colombia, Kenya, and India.

The company measures tons of $\mathrm{CO}_{2} \mathrm{e}$ mitigated, tons of treated waste, biogas produced, trees saved, and hectares per year enhanced with biofertilizer. It does not measure the benefits of avoided deforestation, time saved, or money saved.

Beneficial Returns (www.beneficialreturns.com) is an impact investment debt fund that provided a loan for Sistema Bio to purchase trucks to strengthen their infrastructure and follow up on their customers. Beneficial Returns uses its own internal assessment tool to evaluate a business's ability to contribute to the environment and community well-being while running a profitable enterprise. In a financial innovation to recognize impact and financial health, Beneficial Returns waives borrowers' final payment if they exceed a predetermined impact target and make their other payments on time. This innovation incentivizes continued attention to impact over maximizing profits during growth, which is a challenge faced for small and growing social enterprises.

Sistema Bio finances its enterprise with grants, equity, and debt. To reach smallholder farmers outside tight (highly controlled or coordinated) value chains, Sistema Bio must pilot its model to market, sell, and monitor the biodigesters in rural environments with weak infrastructure and limited farmers' awareness of the benefits of biodigesters, yet great opportunity for adding value. While Sistema Bio could be more profitable if it sold only to larger farmers closer to commercial hubs, 
it decided to run its for-profit enterprise to reach underserved communities. It envisions financial sustainability with high social impact and enhanced soil health.

\section{TCA Rapid Assessment}

In each of the four capitals, Sistema Bio scores well on select services; for example, in Natural Capital, provision and regulating services of air and water were key. In Human Capital, improving farmer livelihood is front and center. The tool underscores the value of Sistema Bio's addition to Social Capital by educating farmers about the biodigester technology and income benefits associated with using biofertilizers for soil health, adding new dimensions because the current questions are focused on "workers" and do not explicitly include customers and other community members. In Produced Capital, recognizing that Sistema Bio works in loose (less controlled) value chains reinforces the value-addition of their business model.

Beneficial Returns as a fund manager found the TCA framework useful to compare one borrower with another, and as a common framework for team members to evaluate an investment opportunity.

\section{Community Markets for Conservation (COMACO)}

A Zambian public good, non-profit company since 2009, Community Markets for Conservation (COMACO) (https://itswild.org) works with 81 community cooperatives in the Luangwa Valley to provide incentives for biodiversity conservation, training, and support services to 188,500 small-scale farmers. This includes agroforestry, organic composting, minimum tillage, crop rotation, and water conservation strategies. They also run a business to manufacture and sell 17 different healthy, pesticide-free, organic, value-added foodstuffs under the brand It's Wild! Products including peanut butter, rice, wild honey, wild mushrooms, dried mango, a soy-based high protein snack, and breakfast cereal, among others.

Their landscape-level conservation approach works on four levels to: 1) engage farmers and former wildlife poachers via cooperatives; 2) ensure food security and improve nutrition; 3) increase individual income through processing and marketing of surplus crops and sustainably harvested wild foods; and 4) enhance biodiversity through payments rewarding collective Conservation Pledges, conservation area set-asides, and soil enhancement practices.

COMACO tracks impact through measuring crop productivity, income, participation, and engagement. Maize yields have improved two to three-fold, on average, and annual incomes for farmers have increased $450 \%$ from $\$ 79$ in 2001 to $\$ 393$ in 2019 . Women represent 52\% of farmers, and 76 former poachers now guard crops in elephant-friendly ways. They recently placed some 29,800 beehives in the community conservation areas.

Most important is how they achieve these impacts by ensuring food security. COMACO will not buy a farmer's production if she does not produce a surplus above what the family needs for its own consumption, but she will still get a cash payment in recognition of commitment to the community conservation district. 
COMACO started with research grants examining the linkages between wildlife poaching, hunger, and food aid to ensure farm families' food security. COMACO asked farmers to sign a Conservation Pledge to reduce wildlife poaching. Today, grants finance training services and expansion strategies, while the food processing business sustains itself from sales in Zambia's major retail stores as well as in schools and hospitals. Carbon sales on international markets contribute to the payments for conservation. COMACO runs two distinct entities side-by-side (non-governmental organization and public good company) in order to separate their respective funding income and expenditures and accomplish their interrelated goals.

\section{TCA Rapid Assessment}

COMACO scores well on all four Natural, Human, Social and Produced Capitals. Their emphasis on increasing Human and Social Capital is particularly strong, with Social Capital as their greatest asset. Since they invest heavily in Human and Social Capital and return all profits within loose supply chains connected to farmer cooperatives, they experience capital constraints in terms of sourcing more investment to expand their approach to other regions.

The model is based on a conservation pledge that is only valid if an entire village signs on, increasing impact by its collective design. Increased pay for crop production is linked to: meeting household food security, adoption of organic farming techniques for increased food production, and the absence of poaching and forest threats. By linking adoption of improved farming techniques to enhanced household nutrition and income, using a lead farmer approach with farmer-to-farmer training as well as a cooperative economic model, COMACO puts farmer ownership at the heart of the work, an intentional strategy that reinforces linkages between different kinds of capital.

COMACO found that having the four areas of capital in one analysis was a helpful way to communicate the impact of the entire enterprise. Despite this, they worry that if a prospective investor only had the tool, they would not be able to weave together the complex self-reinforcing work strands into a meaningful story. A key to success for them is to understand what is working for communities. To what degree is young talent retained in rural areas? To what degree do women participate? How is the enterprise stimulating the environment around it in a way that further engages the communities? The feedback from COMACO points to the importance of expanding the tool to help investors consider how the outcomes in the Four Capitals impact the overall food and agricultural system in which it operates.

\section{Root Capital}

Founded in 1999, Root Capital (www.rootcapital.org) is a non-profit social investment fund growing prosperity for rural farmers in Latin America, Sub-Saharan Africa, and Southeast Asia by investing in the businesses that collect, aggregate, process, and market their crops. These businesses provide farmers with fertilizer, better seed varieties, and training on agricultural methods; connect farmers to international 
markets where their crops fetch a better price; and help farmers to achieve higher and more stable incomes. Root Capital links farmers to markets for sustainably produced goods (or "green markets"), provides assistance on sustainable farm practices, and promotes climate change mitigation and adaptation. Root Capital focuses on companies working with smallholder farmers in formalized, consolidated markets in tight value chains (Rural and Agricultural Finance Learning Labs, n.d.). with clear standards and specific contractual obligations, mostly involving high-value crops (e.g., coffee and cocoa cooperatives).

Through the first quarter of 2020 Root Capital provided financing to 726 businesses working with over 1.5 million smallholder farmers, including some half-amillion women. The businesses Root Capital reached paid nearly $\$ 5$ billion directly to producers. Through on-site training, centralized workshops, and remote engagements, Root Capital has also trained 1,517 enterprises on strategic, financial, and operational skills (Root Capital, 2020).

In order to fulfill its high-impact mission, Root relies on a blend of creative investment capital, philanthropy, and guarantees. For its loan portfolio, Root Capital has solicited investment capital from over 200 institutional, public, and private investors, raising both concessional capital with a small return on investment (ranging from 0.5-2.5\%) and patient, subordinated debt through a notes program. Root Capital also raises philanthropic equity that stays on the lending balance sheet to cover write-offs, as well as loan guarantees, which enable Root Capital to expand to new geographies and value chains. Finally, Root Capital raises grants for operational and non-lending programs, such as impact measurement, technical assistance, and training to agri-businesses, and building the impact investing field.

Root Capital focuses on increasing access to finance for agricultural enterprises that are locked out of traditional financial markets. Here, Root Capital uses the concept of financial "additionality" or of "investor contribution," which refers to the agri-business's ability to obtain a similar loan—a loan of similar size, for the same purpose, with similar collateral, and for a similar rate and fee-from another source, such as a commercial bank. Investors and enterprises that are workingand sharing power-with people and communities who are systematically shut out of financial systems are more likely to contribute to systems transformation.

\section{TCA Rapid Assessment}

Root Capital scores well in all four Capitals of the TEEBAgriFood framework. Root provides loans and training to agribusinesses who in turn promote sustainable farming practices that enhance Natural Capital, including soil and water quality, and improve ecosystem services. Root Capital's loans improve Human Capital by improving smallholder farmers' working conditions and incomes. The companies they invest in improve employee wellbeing, working conditions, skills and training, and provide employment security. Root Capital contributes to increasing Social Capital by strengthening ties between the agribusiness and their farmer suppliers. Root Capital increases Produced Capital by, for instance, strengthening farmer engagement in supply chains, and building financial infrastructure where none exists. 
Root Capital seeks to first and foremost improve the prosperity of rural communities by partnering with agricultural enterprises that increase farmer incomes, create jobs, and contribute to ecosystem health. Root Capital applies a negative screen for egregious practices (e.g., child labor) and then applies a positive impact screen that enables Root to invest in enterprises that are higher risk, more challenging and highly additional and balance those investments with more stable and profitable loans.

\section{Balancing risk and impact in a portfolio}

Root Capital has been a pioneer in developing quantitative impact due diligence tools and facilitating investors' movement towards integrating impact into financial decision making. As part of its loan due diligence process, Root Capital compares each loan's prospective social and environmental impact to its risk-adjusted, expected financial returns to ensure that the portfolio effectively balances financial return and expected impact. Root Capital uses this method to improve their decisions around capital allocation and portfolio goal setting (McCreless, 2017; Impact Frontiers Collaboration, 2020).

\section{Analysis}

We found that the language of the TCA tool does not always resonate with the investors and entrepreneurs whom we interviewed. In particular, many

Table 15.1 Comparison of Four Capitals Across Different Enterprises

\begin{tabular}{|c|c|c|c|c|}
\hline & Natural Capital & Human Capital & Social Capital & Produced Capital \\
\hline $\begin{array}{l}\text { Sistema } \\
\text { Bio }\end{array}$ & $\begin{array}{l}\text { Greenhouse } \\
\text { gas emissions, } \\
\text { food waste, } \\
\text { biodiversity } \\
\text { loss, provi- } \\
\text { sioning (bio- } \\
\text { inputs), soil } \\
\text { enhancement }\end{array}$ & $\begin{array}{l}\text { Farmer income } \\
\text { and knowledge }\end{array}$ & $\begin{array}{l}\text { Community } \\
\text { wellbeing }\end{array}$ & $\begin{array}{l}\text { Units produced, } \\
\text { repayments, } \\
\text { synthetic inputs }\end{array}$ \\
\hline COMACO & $\begin{array}{l}\text { Biodiversity } \\
\text { loss, nutrient } \\
\text { cycling/soil } \\
\text { enhancement } \\
\text { practices }\end{array}$ & $\begin{array}{l}\text { Farmer well- } \\
\text { being, farmer } \\
\text { health/con- } \\
\text { sumer health }\end{array}$ & $\begin{array}{l}\text { Food security, } \\
\text { social coopera- } \\
\text { tion/cooperatives, } \\
\text { collective values }\end{array}$ & $\begin{array}{l}\text { Crop pro- } \\
\text { ductivity, } \\
\text { income, } \\
\text { marketing }\end{array}$ \\
\hline $\begin{array}{l}\text { Root } \\
\text { Capital }\end{array}$ & $\begin{array}{l}\text { Provisioning } \\
\text { (bio-inputs), } \\
\text { soil quality, } \\
\text { water quality, } \\
\text { ecosystem } \\
\text { services }\end{array}$ & $\begin{array}{l}\text { Worker well- } \\
\text { being, working } \\
\text { conditions }\end{array}$ & $\begin{array}{l}\text { Collective } \\
\text { knowledge, } \\
\text { training, supply } \\
\text { chain relationships }\end{array}$ & $\begin{array}{l}\text { Income, market } \\
\text { access, financial } \\
\text { infrastructure }\end{array}$ \\
\hline
\end{tabular}

This table provides a summary of these three entities' impacts in the four Capitals: Natural, Human, Social, and Produced. As the table shows, the use of the four Capitals enables comparison of their relative strengths as an enterprise or fund. 
organizations are working to improve the lives of farmers, their families, and their communities, including their health and well-being. The use of "worker" as the sole term to describe impacts within Human Capital limits the way investors and entrepreneurs understand who is engaged in the "work." Also, the limited exploration of health outcomes such as nutrient density as a result of enhanced soil health, biodiverse local diets, or culturally relevant diets that reflect local practices in the Human and Social Capital section misses key outcomes.

Although the three examples - and many social enterprises-score in all four Capitals, the interactions among the four Capitals differ significantly in local, regional, and global food systems contexts. The TCA tools provide a starting point to explore the interrelationships between impacts in the four Capitals, but should be expanded to more deeply consider systems-level outcomes.

Systems transformation requires important - and difficult - work to strengthen Social Capital. We found that the current Rapid Assessment, while it incorporates questions related to social networks, shared norms, and collective knowledge and values, offers a limited view of Social Capital. For instance, it does not capture important and complex power dynamics between people, within and among communities, and between people and institutions. Finding opportunities for transformative change in local economics and social relationships is part of the genius of these enterprises and funds. These opportunities spring from a complex mix of social knowledge, innovative approaches, the creation or enhancement of markets, creative finance, and other factors which result from strong place-based knowledge, mutual respect, and community relationships.

Understanding the impacts and outcomes of enterprises and investment funds on complex systems requires consideration across Capitals, including the interrelationships, interactions, and trade-offs across the Capitals. Future versions of the Rapid Assessment tools should create opportunities to explore potential and real transformational effects of investments in the food and agricultural sectors.

\section{Synthesis}

The TIFS initiative is developing practical tools that inform investment decisions by holistically considering the human, social, and environmental impacts of enterprises. In writing this chapter, we wanted to test how the TCA tool had additive value for investors and entrepreneurs working to transform food systems. As described above, the cases illustrate how they have combined diverse sources of capital to meet their missions and tailored ways of measuring their outcomes that traverse the four capitals in the model. Our early analysis reveals a mixed outcome for the true cost accounting framework underlying our Assessment tools. In order for the TCA tool to be more relevant for those in the investing and social entrepreneur community interested in transforming food systems, we will need to modify the TCA tool beyond its current form. Below, we outline three high-level considerations for continuing our work with the tools to make it more effectively benefit investors and entrepreneurs seeking systems transformation.

Comprehensive and Standard Frameworks Enable Insights: As demonstrated by the cases, the four Capitals framework enables a comprehensive look at 
how an enterprise or a fund incorporates each element: Natural, Human, Social, and Produced. Often, when enterprises or funds present themselves, they focus on one or two capitals without acknowledging the relevance of or their impact in the other areas. All of the interviewees noted that the four Capitals approach enabled them to be more inclusive in their self-assessment inventory. Several scored well on multiple dimensions of the four Capitals providing yet another point of comparison. For this reason, the TCA framework helps to build the case for both a comprehensive and a standardized framework that incorporates all four Capitals.

Discrete Metrics Downplay Holistic Analysis: Evaluating the four Capitals through a series of discrete metrics, by necessity, requires the simplification of complex relationships and feedback loops between factors that enable a social enterprise or investment to return value to the community and/or farmer. Our Rapid Assessment adaptation did not examine the interrelationships between catalytic elements in the cases, hiding a critical dimension of the analysis. In each of the cases, the enterprise/fund worked hard to incorporate elements within Produced and Social capital that would enable increases in the Natural and Human capital elements. Holistic analysis pays attention to the whole picture including the interrelationships and feedback loops between the four Capitals.

Transformational Nature of Enterprise/Fund: One of the key reasons for the creation of the TCA framework's four Capital approach is to highlight the extractive nature of an economic system that primarily values only Produced Capital. For enterprises and funds, this remains a critical challenge as they are attempting to create increases within the four Capitals while also being financially positive in contexts of historic and ongoing extraction of people, cultures, and nature, in areas of limited infrastructure, and ongoing political and economic power asymmetries. All of the cases add value through training, infrastructure, knowledge exchange, and engaging with farming communities, each of which requires time, new relationships, and investment-yet another hurdle for profitability. The cases remind us that food system transformation requires asking the uncomfortable question of: how should the profits from enterprises be distributed, and to whom? The TCA framework points to these issues and - with necessary improvementscan inform the development of tools that help investors, fund managers, entrepreneurs, and communities to give equal consideration to the four Capitals.

\section{Conclusion}

Frameworks like True Cost Accounting start to make concrete the mantra "what gets measured gets managed" to include non-financial attributes that do not yet have standardized and accepted measurements for return. In the future, tools such as integrated profit and loss statements can create standard approaches to measure companies' performance across the four Capitals. For examples of frameworks for integrated profit and loss statements, see Harvard University Impact Weighted Accounts Project (Harvard Business School, n.d.) and the Impact Institute (Impact Institute, n.d.). This is slow and deliberate work that requires different voices and competing interests to work together. However, investors and entrepreneurs need better tools now to make informed decisions and are not waiting for new 
accounting agreements. They need and want systems-based tools that inform them about how to place investments and demonstrate the value of their businesses that simultaneously address multiple outcomes and drive towards the transformation required for our food system to meet the synergistic needs of humans and the environment.

The TIFS Community understands the urgency of this work and is organizing partners to develop tools, information, and strategies to address the needs of investors and entrepreneurs to track the systemic and transformational outcomes of their work and the types of financing required for such change.

We offer our tools, community, and values in an effort to influence and persuade the broader field of impact investing to envision the real costs of finance and what it will take to change how those decisions are made. By engaging with investors and entrepreneurs who are making hard choices, doing the real work, and being innovative, we believe that our collective actions can influence capital flows toward those that are truly transforming food systems.

\section{References}

CNote. (2019). The History of Socially Responsible Investing. Availablae at: www. mycnote.com/blog/the-history-of-socially-responsible-investing/.

Global Alliance for The Future of Food. (2020). Principles and the Future of Food. Available at: https://futureoffood.org/wp-content/uploads/2020/03/Principles-andthe-Future-of-Food-2020-03-10.pdf.

Global Sustainable Investment Alliance. (2019). 2018 Global Sustainable Investment Review.

Harvard Business School. (n.d.). Impact Weighted Accounts Project. Available at: www. hbs.edu/impact-weighted-acounts/Pages/default.aspx\#: :text=The\%20mission\%20of $\% 20$ the $\% 20$ Impact, $\% 2$ C\%20social\%2C\%20and $\% 20$ environmental\%20performance.

Impact Institute. (n.d.). Integrated Reporting and Integrated Profit Loss. Available at: www.impactinstitute.com/areas-of-expertise/integrated-reporting-and-ipl.

Mooney, A. (2020). ESG passes the Covid challenge. Financial Times,, June 1, 2020. Available at: www.ft.com/content/50eb893d-98ae-4a8f-8fec-75aa1bb98a48.

Root Capital. (2020). Q1 2020 Quarterly Performance Report. Available at: https:// rootcapital.org/about-us/financial-information/.

RSF Social Finance. (n.d.). About Us. Available at: https://rsfsocialfinance.org/our-story/ how-we-work/integrated-capital.

Rural and Agricultural Finance Learning Labs. (n.d.). Value Chain Development. Available at: www.raflearning.org/topics/value-chain-development. 